\title{
As contribuições dos conselhos municipais de meio ambiente para a conservação dos recursos hídricos
}

O presente estudo se propôs a compreender as contribuições dos Conselhos Municipais de Meio Ambiente - CODEMAs na conservação dos recursos hídricos. Para isso, realizou-se uma pesquisa de abordagem qualitativa do tipo estudo de caso único em um CODEMA da Região Sul de Minas Gerais. Utilizou-se como método de coleta de dados a entrevista semiestruturada e a análise documental. Para coleta de dados, realizou-se entre 2018 e 2019 entrevistas semiestruturadas com integrantes deste CODEMA com o intuito de identificar e compreender as suas ações voltadas para a conservação dos recursos hídricos e conhecer a posição de um membro do Ministério Público com relação a esta temática. As análises foram realizadas por meio da técnica de codificação que permitiu o estabelecimento de categorias analíticas. Ao final, foi possível perceber a importância das deliberações do CODEMA na conservação dos recursos hídricos, principalmente no exercício de suas competências como na análise da viabilidade locacional e ambiental de loteamentos, de alvará de localização e autorização em APP urbana, o que a teoria e a legislação que regula o seu funcionamento não evidenciava até o momento. Quanto às limitações, não se pode generalizar os dados adquiridos para outros CODEMAs, já que cada um possui suas próprias competências delimitadas na lei de sua criação.

\section{The contributions of municipal environmental councils to the conservation of water resources}

\begin{abstract}
This study aimed to understand the contributions of Municipal Councils for the Environment - CODEMAs in the conservation of water resources. For that, a qualitative research of the type of single case study was carried out in a CODEMA of the South Region of Minas Gerais. Semi-structured interviews and document analysis were used as the data collection method. For data collection, between 2018 and 2019, semi-structured interviews were conducted with members of this CODEMA in order to identify and understand their actions aimed at the conservation of water resources and to know the position of a member of the Public Ministry regarding this topic. The analyzes were performed using the coding technique that allowed the establishment of analytical categories. In the end, it was possible to perceive the importance of CODEMA's deliberations in the conservation of water resources, mainly in the exercise of its competences, such as in the analysis of the locational and environmental feasibility of subdivisions, of localization permit and authorization in urban APP, which the theory and the legislation that regulates its operation did not show up until now. As for the limitations, it is not possible to generalize the acquired data to other CODEMAs, since each one has its own competences delimited in the law of its creation.
\end{abstract}

Keywords: Municipal environmental management; Environmental legislation; Water resources.

Topic: Planejamento, Gestão e Políticas Públicas Ambientais

Reviewed anonymously in the process of blind peer.
Received: 02/12/2020

Approved: 23/12/2020
Daiane Fernandes Pereira Lahmann Universidade Vale do Rio Verde, Brasil http://lattes.cnpq.br/6972291289092668 http://orcid.org/0000-0002-0111-6094 daianeviannajr@yahoo.com.br

Letícia Rodrigues da Fonseca

Universidade Vale do Rio Verde, Brasil http://lattes.cnpq.br/4847209046603133

http://orcid.org/0000-0002-3528-2090

leticia.rodrigues.vga@gmail.com

Sheldon William Silva (iD)

Universidade Federal de Lavras, Brasil http://lattes.cnpq.br/5691436224279198

http://orcid.org/0000-0002-2473-5728

sheldon.silva@ifmg.edu.br

\author{
Marcelo Ribeiro Silva (10) \\ Universidade Federal do Mato Grosso, Brasil \\ http://lattes.cnpq.br/1113479347390844 \\ http://orcid.org/0000-0002-5903-0023 \\ profmarceloufms@hotmail.com
}

Referencing this:

LAHMANN, D. F. P.; FONSECA, L. R.; SILVA, S. W.; SILVA, M. R.. As contribuições dos conselhos municipais de meio ambiente para a conservação dos recursos hídricos. Revista lbero Americana de Ciências Ambientais, v.11, n.7, p.703-721, 2020. DOI: http://doi.org/10.6008/CBPC2179-6858.2020.007.0054 


\section{INTRODUÇÃO}

Com a descentralização da gestão ambiental ocorrida principalmente com o advento da Política Nacional de Meio Ambiente (Lei 6.938/81) e, posteriormente, com a promulgação da Constituição Federal de 1988, os municípios se viram obrigados a criarem seu Sistema Municipal de Meio Ambiente - SISMUNA e o seu respectivo Conselho Municipal de Meio Ambiente - CODEMA. Como órgãos deliberativos e democráticos, os CODEMAs possuem como principal função possibilitar a participação da comunidade local e a municipalização da gestão ambiental por meio da execução de políticas ambientais e, consequentemente, ampliar a atuação da Administração Pública (LEME, 2010).

Com relação aos recursos hídricos, a Política Nacional de Recursos Hídricos determinou a sua gestão integrada à gestão ambiental de forma descentralizada e com a participação do poder público, dos usuários e das comunidades (BRASIL, 1997). Uma gestão integrada entre os recursos hídricos e o meio ambiente se apresenta como uma medida eficaz na redução das vulnerabilidades presentes nos municípios, além de ser uma forma de aumentar a adaptação de populações à condição de seca e escassez de água (OLIVEIRA et al., 2017).

Nesse sentido, acredita-se que os CODEMAs contribuem positivamente para a conservação dos recursos hídricos, pois sem a atuação dos conselhos municipais, dificulta-se a gestão dos impactos negativos na utilização do solo e dos recursos hídricos, advindos de uma ocupação desordenada dos espaços. No entanto, este tema, especificamente a forma de contribuição dos CODEMAs, não é descrita e explorada na literatura ou nas determinações legais que regulamentam a sua atuação. A literatura sobre gestão e conservação dos recursos hídricos é mais voltada para os comitês de bacia hidrográfica, uma vez que a bacia hidrográfica é a unidade territorial para implementação da Política Nacional de Recursos Hídricos e atuação do Sistema Nacional de Gerenciamento de Recursos Hídricos, conforme determina a Lei das Águas (Lei 9433/97). Assim, não há uma análise no âmbito municipal e da integração dos recursos hídricos com a gestão ambiental, especialmente relacionados às decisões dos conselhos municipais de meio ambiente.

Diante deste cenário, o presente estudo propõe, como objetivo geral, compreender as contribuições dos CODEMAs na conservação dos recursos hídricos. Já, como objetivos específicos pretende-se: (i) descrever as competências desempenhadas pelo CODEMA em análise que são voltadas para a conservação dos recursos hídricos; (ii) descrever as estratégias e os recursos utilizados pelo CODEMA na busca pela conservação dos recursos hídricos. Acrescenta-se que este artigo é parte de um estudo mais amplo, decorrente de uma dissertação de mestrado que buscou descrever diretrizes para a estruturação de CODEMAs. Além da relevância social, justifica-se a realização desta pesquisa pela demanda por conhecimento científico e acadêmico na área.

\section{REVISÃO TEÓRICA}

\section{O envolvimento dos CODEMAS com a gestão dos recursos hídricos}

A lei que instituiu a Política Nacional de Recursos Hídricos (lei 9.433/97) busca garantir o uso múltiplo 
de reservatórios de forma disciplinada (GALVÃO et al., 2015), sendo que o processo de decisão e implementação de políticas sobre a gestão das águas envolve uma gama de atores sociais - públicos, privados e não governamentais - inseridos em distintas arenas, articulados e rearticulados continuamente numa teia de relações (ASSIS et al., 2008).

Pesquisas têm comprovado a relação direta entre o uso e ocupação do solo com a conservação dos recursos hídricos. Cita-se o caso que ocorreu em Caxias do Sul no qual se constatou que a baixa qualidade da água era um dos reflexos do lançamento de efluentes de fontes pontuais (residências e indústrias), que não receberam tratamento adequado conforme os padrões de lançamento previstos pela legislação devido à ausência de estação de tratamento de efluentes (CORNELLI et al., 2016).

Para evidenciar como os CODEMAS podem contribuir para se evitar esta situação, pode-se citar o processo de licenciamento para aprovação de instalação de empreendimentos de impacto local, bem como a análise de loteamentos quando designados em lei, como no Plano Diretor, competindo aos municípios o licenciamento ambiental de empreendimentos e atividades de impacto ambiental local e aquelas que the forem delegadas pelo estado por instrumento legal ou convênio (BRASIL, 1997).

O objetivo deste procedimento é prevenir a ocorrência de danos ambientais, ao pautar-se no Princípio da Prevenção (CARVALHO, 2005), isso porque, quando se trata de meio ambiente, os danos são, em sua maioria, irreparáveis e irremediáveis e quando existe possibilidade de reparação, os investimentos necessários são muito altos, sem a garantia de retornar ao estado original. Por essa razão, é indispensável a utilização de mecanismos que possam ajudar a minimizar esses danos (PARDO-MARTíNEZ et al., 2017).

De acordo com a Lei de Uso e Ocupação do Solo (Lei no 6766/79), o parcelamento do solo se dá mediante desmembramento ou loteamento, sendo que este último é entendido como a subdivisão de gleba em lotes destinados a edificação, com abertura de novas vias de circulação, de logradouros públicos ou prolongamento, modificação ou ampliação das vias existentes (BRASIL, 1979).

Este preceito legal exige que um loteamento tenha uma infraestrutura básica, a qual deverá ser constituída pelos equipamentos urbanos de escoamento das águas pluviais, iluminação pública, esgotamento sanitário, abastecimento de água potável, energia elétrica pública e domiciliar e vias de circulação. Assim, o projeto de loteamento exige um trabalho de estudo do solo, topografia, drenagem e de rede de água e esgoto, requisitos estes que deverão ser analisados pelos conselheiros do CODEMA para a sua aprovação.

Em Itajubá - MG, o Plano Diretor estipula que os parcelamentos com área menor de 25 ha ficarão sujeitos ao CODEMA. Em estudo realizado neste Conselho, constatou-se a falta de sua ação no cumprimento das diretrizes para a expansão urbana no caso de implantação de um loteamento denominado Paraíso, pois este apresentava processo erosivo (SILVA, 2015).

Por outro lado, no CODEMA de Campo Grande - MS, identificou-se que a maioria dos processos de licenciamento analisados por aquele Conselho tratava-se de obras viárias e de recuperação de fundos de vale, demonstrando que a expansão da cidade, o crescimento do número de veículos e a impermeabilização do solo ocasionaram intervenções em APPs - áreas de preservação permanente e problemas ambientais 
graves no município (ALMEIDA NETO et al., 2011). Nesta pesquisa também se comprovou a existência de processos licenciatórios de atividades extrativistas, que resultaram em impactos ambientais frequentes aos recursos hídricos, posto que sua matéria-prima, areia, é extraída principalmente do leito dos cursos d’água (ALMEIDA NETO et al., 2011).

Para prevenir ou minimizar estes impactos ambientais, Castro et al. (1999) propõe a criação de câmaras técnicas dentro dos CODEMAS para tratar sobre o uso e ocupação do solo e outras questões relacionadas ao meio ambiente no município como transportes, saneamento ambiental e arborização urbana, proporcionando assim, divisão de tarefas e maior responsabilidade por parte dos conselheiros em sua ação representativa neste órgão colegiado. O CODEMA pode ainda adotar outras medidas, como foi o caso do CODEMA de Patos de Minas - MG que passou a exigir nos projetos de loteamento, o isolamento das APPs e das áreas de proteção ambiental, e que estas façam limites com ruas, de modo a prevenir a extensão irregular dos fundos dos imóveis, o que não ocorria no passado (AMARAL et al., 2013).

Portanto, estes casos descritos corroboram com o que é proposto por Oliveira et al. (2017) que propõem a hipótese de que os municípios com maiores níveis de implementação de mecanismos de gestão por meio dos CODEMAs, são menos vulneráveis aos efeitos do uso e ocupação desordenados do solo.

Além dessas competências, os CODEMAS podem ser responsáveis pela autorização de intervenção ou supressão em APPs urbanas, uma vez que de acordo com a legislação vigente, a competência é do município, salvo quando é resultante de empreendimento sujeito a licenciamento ambiental de nível estadual, porque neste caso, a autorização será requerida no próprio processo de licenciamento (BRASIL, 2011).

Conforme a Resolução CONAMA no. 369/06, a autorização de intervenção ou supressão dependerá de autorização do órgão municipal desde que o município possua CODEMA, com caráter deliberativo, e Plano Diretor ou Lei de Diretrizes Urbanas, no caso de municípios com menos de vinte mil habitantes, mediante anuência prévia do órgão ambiental estadual competente, fundamentada em parecer técnico. Assim, sendo o CODEMA deliberativo, este será o responsável pela análise e deliberação desses pedidos.

Para Oluwatuyi et al. (2017) e Ferreira et al. (2019), as APPs denominadas matas ciliares possuem uma importância fundamental na conservação dos recursos hídricos, pois atuam como barreiras naturais impedindo a poluição dos cursos d'água e agem como filtro natural para a água, garantindo a continuação do seu ciclo e impedindo a ocorrência de processos erosivos, deslizamento de encostas e assoreamento. Considerada como medida de caráter de exceção, as intervenções em APPs somente podem ser deferidas nas hipóteses de utilidade pública, de interesse social ou de baixo impacto ambiental, previstas no código Florestal Brasileiro (BRASIL, 2012). No entanto, o que se verifica na prática quando ocorre a aprovação de projetos urbanísticos de parcelamento do solo que comtemplem essas APPs pelos municípios é que não são implantadas medidas de proteção e fiscalização, favorecendo problemas como processos erosivos, instabilidade de terrenos e deslizamentos de massa, assoreamento dos corpos d'água e diminuição na qualidade dos recursos hídricos (LUCON et al., 2019).

A baixa integração entre os estudos ambientais e as respostas dos órgãos aos problemas 
encontrados, leva a uma falha na implementação de políticas que visem um uso consciente dos recursos naturais, causando uma piora no quadro de danos ambientais. É premente, pois, identificar de que forma os CODEMAs podem atuar mais ativamente na melhoria da gestão ambiental para propor soluções aos problemas identificados.

\section{MATERIAIS E MÉTODOS}

Considerando o objetivo deste estudo, optou-se por realizar uma pesquisa de abordagem qualitativa que busca por explicações a respeito de um problema ou questão, por meio da avaliação de informações ou experiências relacionadas ao fenômeno em questão (COLLIS et al., 2005). Este trabalho pode ser considerado ainda como um estudo de caso único, utilizado quando há necessidade de estudar as atividades, particularidades e complexidades de um determinado caso, dentro de circunstâncias importantes (STAKE, 2000).

Dentro do Sistema Municipal Ambiental, o CODEMA pesquisado pertence a um município da Região Sul de Minas Gerais e foi criado por meio da Lei Municipal no 1.498, de 22 de março de 1984. Em 1995, por meio da Lei Municipal no 20/95 que definiu vinte e uma competências este CODEMA foi reestruturado, sendo determinado que seria um órgão local, com jurisdição em todo território do município, além de consultivo e de composição colegiada com a finalidade de assessorar o poder municipal na proteção, conservação e melhoria do meio ambiente. Já, em maio de 2004, a Lei supracitada foi alterada pela Lei no 182/2004, com duas mudanças significativas na estrutura deste CODEMA. Este passou a ser, além de consultivo, deliberativo e competente por emitir parecer conclusivo sobre os pedidos de alvará de localização, e concessivo de licença de atividades poluidoras e/ou de recursos ambientais dirigidos ao município.

Para coleta de dados, realizou-se entre 2018 e 2019 entrevistas semiestruturadas com integrantes deste CODEMA (quadro 1) com o intuito de identificar e compreender as suas ações voltadas para a conservação dos recursos hídricos e conhecer a posição de um membro do Ministério Público com relação a esta temática.

Quadro 1: Caracterização dos entrevistados.

\begin{tabular}{|l|l|}
\hline ENTREVISTADO & CARGO OU FUNÇÃO \\
\hline Entrevistado 1 & Secretário Executivo do CODEMA e Chefe da Secretaria Municipal do Meio Ambiente do Município \\
\hline Entrevistado 2 & Presidente do CODEMA e Secretário de Meio Ambiente e Agricultura \\
\hline Entrevistado 3 & Conselheira do CODEMA e Representante da Sociedade Civil \\
\hline Entrevistado 4 & Promotor de Justiça de Minas Gerais \\
\hline
\end{tabular}

Além disso, efetuou-se uma análise documental (MALHOTRA, 2006) por meio da avaliação de documentos oficiais do CODEMA pesquisado, principalmente suas atas de assembleia realizadas no período de outubro de 2018 a julho de 2019 (18/10/18; 29/11/18; 13/12/18; 11/02/19; 20/03/19; 17/04/19; 04/04/19) e legislações ambientais federais e estaduais. A análise documental forneceu complementações na interpretação e validou as informações coletadas nas entrevistas, além de proporcionar a descoberta de outras questões essenciais ao estudo que mereciam ser mais exploradas (YIN, 2005).

Com base na análise documental e na disposição legal sobre o tema, elaborou-se uma matriz de 
amarração para o desenvolvimento do roteiro de entrevista que possibilitou atender aos objetivos deste trabalho, e que é apresentada no Quadro 2 na sequência.

Quadro 2: Matriz de amarração para elaboração do roteiro da entrevista

\begin{tabular}{|c|c|c|}
\hline Categoria & Autores/ Leis & Questionamentos \\
\hline $\begin{array}{l}\text { Conservação dos } \\
\text { Recursos Hídricos }\end{array}$ & $\begin{array}{l}\text { - Novicki e Souza (2010) } \\
\text { - DN COPAM no 213/2017 (art. } \\
\text { 1ㅇ, §2o, inciso VIII). } \\
\text { - Resolução CONAMA n.o } \\
\text { 237/1997 (art. 6o) } \\
\text { - Lei Complementar n. 140/ } \\
2011 \text { (art. 9o, inciso XIV); } \\
\text { - Almeida Neto, Oliveira e } \\
\text { Bononi (2011); } \\
\text {-Silva (2015); } \\
\text {-Amaral, Pereira e Borges } \\
\text { (2013); } \\
\text { Deliberação COPAM n.o 76/04 } \\
\text { (art.3요, §2); } \\
\text { - Cornelli et al. (2016); } \\
\text {-Oliveira, Lima e Sousa (2017); }\end{array}$ & $\begin{array}{l}\text { (1) Quais as atribuições do CODEMA? } \\
\text { (2) O CODEMA atua na educação ambiental? } \\
\text { (3) O município realiza o licenciamento? } \\
\text { (4) O CODEMA exige ou exigia algum tipo de estudo, como estudo de } \\
\text { impacto de vizinhança? } \\
\text { (5) Você já participou de alguma proposta de diretriz para a política } \\
\text { municipal ambiental ou a propositura de normas técnicas? Se sim, } \\
\text { como foi? } \\
\text { (6) O CODEMA já propôs ao Executivo municipal a instituição de } \\
\text { alguma unidade de conservação? Tem perspectiva para isso? } \\
\text { (7) Qual a importância de um CODEMA para a conservação dos } \\
\text { recursos hídricos? } \\
\text { (8) O CODEMA é responsável por autorizar as intervenções em APP } \\
\text { urbana no município? } \\
\text { (9) O CODEMA é responsável pela aprovação de loteamentos? } \\
\text { (10) O CODEMA realiza a identificação de áreas degradadas ou } \\
\text { ameaçadas de degradação? } \\
\text { (11) O CODEMA recebe representações da população? Se sim, como } \\
\text { se procede neste caso? }\end{array}$ \\
\hline
\end{tabular}

As entrevistas foram transcritas para, posteriormente, se realizar uma leitura cuidadosa com o intuito de identificar trechos dos textos que apresentavam informações relacionadas às competências do CODEMA identificadas a partir da análise documental e da disposição legal por meio da técnica de codificação.

A técnica de codificação define sobre o que se trata os dados em análise e envolve a identificação e o registro de uma ou mais passagens de texto, como partes de um quadro geral que, em algum sentido, exemplificam a mesma ideia teórica e descritiva. Geralmente, várias passagens são identificadas e relacionadas com uma ideia. Sendo assim, todo o texto, entre outros elementos que se refere à mesma coisa ou exemplifica a mesma coisa é agrupado e codificado com o mesmo nome. A codificação é uma forma de indexar ou categorizar o texto para se estabelecer uma estrutura de ideias temáticas em relação a ele (GIBBS, 2009). A categoria geral é denominada 'código pai' que neste estudo corresponde a cada uma das competências exercidas pelo CODEMA pesquisado, como por exemplo, conscientização pública por meio da EA. Já a categoria associada à geral, é denominada 'código filho', que neste caso, representam os trechos de entrevista e dos documentos analisados relacionados a cada competência. Os dados obtidos por meio das entrevistas possibilitaram o entendimento do contexto deste órgão e, consequentemente, a sua atuação em prol da conservação dos recursos hídricos.

\section{RESULTADOS E DISCUSSÃO}

Ao final do trabalho foi possível concluir a contribuição dos CODEMAs na conservação dos recursos hídricos no exercício de algumas de suas competências conforme pode ser analisado na figura 1 a seguir: 


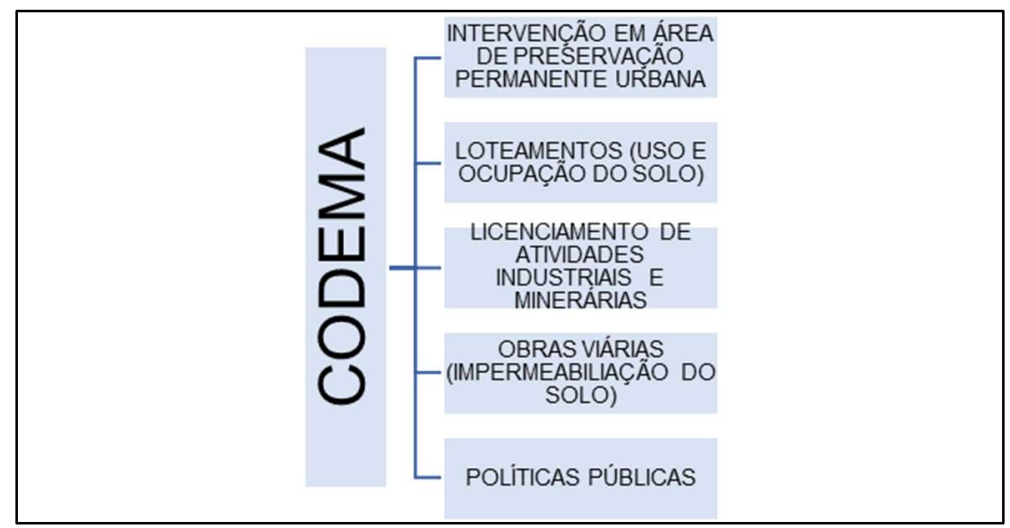

Figura 1: Contribuições do CODEMA na conservação dos recursos hídricos.

No CODEMA analisado, ao instituir sua lei de restruturação n. 606/2017, o mesmo previu vinte e sete competências: 1)formular as diretrizes para política municipal do meio ambiente; 2) propor normas legais, procedimentos e ações, visando à defesa, conservação, recuperação e melhoria da qualidade ambiental no município; 3)exercer a orientação da ação fiscalizadora de observância às normas contidas na Lei Orgânica Municipal e na legislação a que se refere o item anterior; 4) obter e repassar informações e subsídios técnicos relativos ao desenvolvimento ambiental aos órgãos públicos, entidades públicas e privadas e à comunidade em geral; 5) atuar na conscientização pública para o desenvolvimento sustentável, promovendo a educação formal e informal; 6) subsidiar o Ministério Público no exercício de suas competências para a proteção do meio ambiente; 7) solicitar aos órgãos competentes o suporte técnico complementar às ações executivas do município na área ambiental; 8) propor a celebração de convênios, parcerias, consórcios, contratos e acordos com entidades públicas e privadas; 9) opinar, previamente, sobre os aspectos ambientais de políticas, planos e programas governamentais que possam interferir na qualidade ambiental municipal; 10) apresentar anualmente, proposta orçamentária ao Executivo Municipal, inerente ao seu funcionamento; 11) identificar e informar a respeito da existência de áreas degradadas ou ameaçadas de degradação; 12) opinar a respeito da realização de estudo alternativo sobre as possíveis consequências ambientais de projetos públicos ou privados; 13) acompanhar o controle permanente das atividades degradadoras e poluidoras; 14) receber denúncias feitas pela população; 15) acionar os órgãos competentes para localizar, reconhecer, mapear e cadastrar os recursos naturais existentes no município, objetivando o controle das ações capazes de afetar ou destruir o meio ambiente; 16) decidir sobre a concessão de licenças ambientais de sua competência; 17) orientar o poder Executivo Municipal acerca do exercício do poder de polícia; 18) deliberar sobre a realização de audiências públicas no processo de instalação de atividades potencialmente poluidoras; 19) propor ao Executivo Municipal a instituição de unidades de conservação; 20) responder à consulta referente à sua competência; 21) decidir, juntamente com o órgão executivo de meio ambiente, acerca da aplicação de recursos provenientes do FMMA- Fundo Municipal de Meio Ambiente; 22) acompanhar as reuniões das Câmaras do COPAM em assuntos do município; 23) apreciar e deliberar sobre a emissão de alvarás, certidões de localização ou declaratórias de empreendimento, já implantados ou visando à implantação; 24) opinar, quando solicitado, sobre a emissão de alvarás de localização e funcionamento no âmbito municipal das atividades potencialmente poluidoras; 25) opinar nos estudos sobre o uso, ocupação 
e parcelamento do solo urbano e posturas municipais, visando à adequação das exigências do meio ambiente, ao desenvolvimento do município; 26) apreciar os requerimentos de declarações referentes à Resolução CONAMA no. 237, art. 10, §1ำ e, 27) e apresentar ao prefeito o projeto de regulamentação daquela lei. Neste estudo não foram analisadas todas as atividades relacionadas às competências, optando-se por aquelas que foram inicialmente identificadas na pesquisa e que serão discriminadas a seguir.

No entanto, observou-se que o exercício de todas as competências pode contribuir direta ou indiretamente para a conservação dos recursos hídricos, conforme parecer encaminhado pelo CODEMA pesquisado:

O CODEMA tem o objetivo de contribuir com a implementação da Política ambiental e questões referentes ao equilíbrio ambiental, desenvolvimento urbano e melhoria da qualidade de vida dos municípios, incluindo a conservação dos recursos hídricos. Dentre algumas competências do CODEMA, estão: 1) formular as diretrizes para política municipal do meio ambiente, incluindo-se as atividades prioritárias de ação do município em relação à proteção e conservação do meio ambiente; 2 ) propor normas legais, procedimentos $\mathrm{e}$ ações, visando à defesa, conservação, recuperação e melhoria da qualidade ambiental no município, observadas as pertinentes legislações federal, estadual e municipal; 3) atuar na conscientização pública para o desenvolvimento sustentável, promovendo a educação ambiental formal e informal, com ênfase nos problemas e peculiaridades do município; 4) opinar, previamente, sobre os aspectos ambientais de políticas, planos e programas governamentais que possam interferir na qualidade ambiental municipal. (Parecer sobre a importância dos CODEMAs na conservação dos recursos hídricos).

À vista disso, foram relatadas neste trabalho algumas decisões constatadas neste CODEMA em prol da conservação dos recursos hídricos, e que se evidenciam por meio das atividades que serão relatadas a seguir.

\section{Formulação de diretrizes para política municipal do meio ambiente}

A formulação de diretrizes é considerada a mais importante das competências de um CODEMA, todavia, pelo que se constatou em ata e entrevista, nunca foi realizada a proposta de qualquer diretriz no CODEMA analisado. As diretrizes são regulamentações que vão garantir a implementação da política do meio ambiente no âmbito municipal.

\section{Conscientização pública por meio da EA}

A educação ambiental - EA é um instrumento indispensável para resolução de conflitos socioambientais em nível municipal. Neste sentido, os CODEMAs exercem papel fundamental, pois podem contribuir de maneira significativa para que ela seja colocada em prática ao promoverem programas, projetos e, em específico, atividades de EA, exigindo dos conselheiros, além da consciência ambiental e conhecimentos, a necessidade de mobilização dos cidadãos em torno das questões ambientais (NOVICKI et al., 2010; CHOON et al., 2017; VARELA-CANDAMIO et al., 2017).

Durante a realização da entrevista preliminar desta pesquisa, percebeu-se a necessidade de envolvimento do CODEMA em mais ações de EA voltadas para a conservação dos recursos hídricos, pois só foi apresentada uma pelo entrevistado 01 que buscou conscientizar a população sobre a importância da coleta seletiva: '[...] campanha que a gente faz constantemente com carro de som incentivando a coleta 
seletiva nos dias e horários, folders e cartazes etc.'. Portanto, essas ações são fundamentais, pois os resíduos sólidos podem causar degradação dos recursos hídricos por meio da poluição e disposição ambientalmente inadequada (CARVALHO et al., 2016; SIMATELE et al., 2017). As águas pluviais podem levar o resíduo depositado nas cidades e o chorume líquido gerado pela decomposição de resíduos orgânicos para o leito dos rios, aumentando a incidência de doenças em seres humanos, além de prejudicar a biota aquática (BABAYEMI et al., 2017; LAW et al., 2017; JIA et al., 2018; CONTRERA et al., 2019). Citam-se também os impactos socioambientais como as enchentes e inundações urbanas. Por isso, defende-se que além de ações voltadas para EA que buscam a sensibilização da população, é preciso ter uma gestão integrada dos recursos hídricos, com maior participação dos municípios, por meio da implantação de políticas de uso e ocupação do solo (PEIXOTO et al., 2019).

Considerando a carência de ações voltadas para a EA e a proximidade da Semana do Meio Ambiente, realizou-se no município um projeto de extensão que envolveu as autoras, o CODEMA pesquisado e outros atores sociais no período de 04 a 08 de junho de 2018. Obtiveram-se neste projeto os seguintes resultados: 1 desenvolvimento de cartilha educacional (Águas de [nome do município pesquisado]); 150 cartilhas educacionais distribuídas; 5 comunidades escolares envolvidas; 500 alunos envolvidos, aproximadamente; 18 plantios de mudas de espécies florestais nativas; 2 palestras sobre conservação dos recursos hídricos; 1 palestra sobre produtos orgânicos; 2 atividades lúdicas (teatro de fantoches e teatro com catadores de uma associação); 1 concurso de desenhos sobre as águas do município; 1 iniciação de horta escolar com doação de sementes, e; 1 um artigo científico publicado.

Na entrevista realizada em 2018, o Entrevistado 03 relatou que o CODEMA ainda não fazia ações voltadas para a EA, mas que, no entanto, gostaria de propor uma após o término de seu mestrado, reconhecendo assim, a importância deste tipo de ação. Evidenciou ainda a dificuldade de realizar a coleta seletiva no município e a necessidade de mobilização da sociedade:

Um dos resultados que eu cheguei é que para a coleta seletiva realmente funcionar, a gente precisa fazer uma mobilização, pois a população não aderiu à separação. Sabe, assim, eu não estudei a fundo o porquê, mas eu sei que a população não separa do jeito que deveria. Aí, eu vou propor um projeto de educação ambiental, mas isso só lá para abril, quando terminar o meu mestrado. (Entrevistado 03)

O Entrevistado 02 relatou a realização de palestras, mas de forma genérica, sem descrever o seu conteúdo, data ou local: '[...] algumas palestras nas escolas, como CODEMA e como Prefeitura também. A gente faz junto. Alguns conselheiros já participaram'. Já, na última entrevista realizada em 2019, o Entrevistado 03 relatou uma palestra que foi ministrada no dia mundial da água pelo CODEMA: 'No Dia Mundial da Água nós fizemos uma palestra pelo CODEMA'.

\section{Proposição de celebração de convênios, parcerias e outros}

De forma a implementar ações de EA, colocar em prática as demais competências e instituir um suporte técnico capacitado, os CODEMAs devem propor a celebração de parcerias e consórcios com entidades públicas e privadas. As parcerias permitem a ação cooperada em diversas áreas como a financeira, técnica, científica, jurídica, administrativa, entre outras, e ao mesmo tempo, permitem uma maior 
participação da sociedade na gestão ambiental, possibilitam o uso eficiente dos recursos públicos e o aperfeiçoamento dos recursos humanos. Por outro lado, com a formulação de consórcios é possível atingir objetivos comuns aos municípios viabilizando, principalmente, recursos financeiros e maior capacitação e treinamento das equipes locais, evidenciando uma solução àqueles que não conseguem estruturar seu sistema de gestão ambiental isoladamente (ÁVILA et al., 2012). No CODEMA pesquisado, foram encontradas duas parcerias importantes: entre o município e a ARPA Rio Grande (acordo de cooperação) que prevê entre outras medidas, apresentar pareceres técnicos de cunho ambiental mediante solicitações formais por parte do município ou do CODEMA. Identificou-se também um consórcio regional de saneamento básico (declaração de cooperação técnica) que disponibiliza dois técnicos para dar suporte necessário ao CODEMA e à Secretaria Municipal de Agricultura, Pecuária e Meio Ambiente.

Ademais, da análise das atas, também foi possível verificar parcerias informais com o IEF - Instituto Estadual de Floresta e com a PMMA- Polícia Militar do Meio Ambiente que auxiliam no caso de dúvidas técnicas, como forma de prevenção no caso de autorização de ações que podem causar significativo impacto ambiental. Durante a análise documental constatou-se este apoio em uma situação que envolveu autorização para supressão de sessenta e oito palmeiras em área particular que estavam colocando em risco o patrimônio público e privado, bem como a população:

O secretário informou que entrou em contato com o IEF e também como a PMMA, através do sargento, suplente deste conselho, e ambas as instituições informaram que pelos indivíduos arbóreos não estarem em APP ou reserva legal e estarem em ambiente urbano, não há impedimento legais com relação à supressão de tal espécie deste que seja autorizada pelo órgão municipal competente.

\section{Apresentação de proposta orçamentária}

O município é responsável por prover o seu CODEMA no âmbito administrativo, técnico e financeiro para possibilitar o seu funcionamento e a efetividade de suas ações e realização de suas competências, principalmente, para o custeio de ações voltadas para EA. Para tanto, é importante que o CODEMA apresente anualmente sua proposta orçamentária ao executivo para que ele possa se programar para o próximo ano sem comprometer os outros setores, o que não foi feito, conforme constatou-se na última entrevista: 'Ainda não. Mas a gente ainda não teve essa reunião para a gente ver, direcionar como que vai ser feito' (Entrevistado 02). No entanto, o Entrevistado 03 enfatizou a necessidade de se ter, primeiramente, um planejamento para se identificar o orçamento necessário para a execução das atividades e ressaltou que o CODEMA está exercendo apenas a competência de deliberar: 'Então, justamente por a gente não ter planejamento não tem como fazer proposta orçamentária. Como é que a gente vai propor se a gente não tem planejamento no que gastar. Por enquanto, o órgão está só deliberando'.

Constatou-se que os conselheiros possuem uma percepção sobre a atual situação do CODEMA que ainda se encontra em fase inicial de estruturação, muito embora tenha sido criado em 1984, mormente porquê das 27 competências previstas em lei, ele exerce apenas aquelas de caráter deliberatório. 


\section{Identificação de áreas degradadas ou ameaçadas de degradação}

Ao identificar e informar a existência de áreas degradadas ou ameaçadas de degradação, o CODEMA contribui para a tomada de providências por parte da Secretaria de Meio Ambiente para a recuperação das áreas afetadas, além de dificultar a ocorrência de dano ambiental nas áreas ameaçadas. Na última entrevista foram citadas áreas que possivelmente estão em situação de risco e necessitam de identificação e fiscalização por parte do município:

Por exemplo, o pessoal que tem costume de deixar o loteamento sujo, depois dessa época de seca, sem chuva, tacar fogo lá. Isso gera um monte de problema, e a Prefeitura não multa esse pessoal. E isso é o que eu vejo de maior conflito, principalmente nessa época. De fiscalizar e manter limpo. Aqui na nossa cidade, estava com um surto de dengue, por exemplo. Pessoal jogando lixo nas esquinas, sujando tudo, jogando lixo na beira de rodovia, em terreno baldio. (Entrevistado 03)

Sendo assim, foi proposto ao CODEMA foco deste estudo, a elaboração de um cronograma para levantamento dessas áreas em cada bairro que deverá ser encaminhado à Secretaria de Meio Ambiente que tem poder de polícia para realizar uma vistoria no local, e, se for o caso, autuar e tomar as providências cabíveis administrativamente, o que não foi cumprido diante da falta de reuniões após o recebimento da recomendação. Esse levantamento poderá servir de subsídio para o município na realização do zoneamento urbano, instrumento da política urbana no qual faz-se um estudo das potencialidades dos riscos que as áreas apresentam (ZAFALON et al., 2012).

\section{Recebimento de representações}

Nas atas analisadas do CODEMA não foi possível identificar se a população faz representações, mas caso isso aconteça, conforme salientado pelo Promotor de Justiça, o CODEMA deverá direcioná-las aos órgãos competentes como a Polícia Militar do Meio Ambiente, a Secretaria de Meio Ambiente (setor de fiscalização) e Ministério Público para apurar as responsabilidades administrativas, cíveis e criminais, atuando assim como catalisador de informações e defensor dos recursos hídricos:

E tem outro aspecto também para destacar que é o seguinte, o CODEMA recebe uma série de reclamações, notícia da polícia militar, de meio ambiente, então meio que ele pode centralizar essas informações e acionar os órgãos. Então, recebeu uma notícia anônima de alguém que está descartando efluente num determinado rio, ele pode pegar aquela notícia e mandar pra PMMA, pode mandar para o Ministério Público. Então, assim, é um catalisador de informações. Eu acho que, com isso, consegue atuar muito bem na defesa dos recursos hídricos. (Entrevistado 04)

\section{Concessão de licenças ambientais}

Conforme anteriormente exposto, os CODEMAS podem ter várias competências/atribuições, sendo que uma delas é o licenciamento ambiental municipal. O CODEMA pesquisado trouxe em sua lei Municipal anterior no 182/2004 (art. 1ํ), o licenciamento como mais uma de suas competências, no entanto, só previa a emissão de parecer acerca das licenças ambientais. Na atual legislação, cabe a ele decidir sobre a concessão de licenças ambientais de sua competência, bem como sobre penalidades, respeitadas as normas estaduais, federais e municipais. Entretanto, apesar de possuir os requisitos impostos pela lei, inclusive um corpo 
técnico mediante a parceria já relatada, o município do CODEMA em comento não realiza o licenciamento de nenhuma atividade.

Ressalta-se que os conselheiros entrevistados entendem que o CODEMA e o município não estão preparados, bem como totalmente estruturados para a realização do licenciamento ambiental municipal, pois necessitam de um corpo técnico dentro do CODEMA: '[...] a gente não tem um suporte técnico dentro do CODEMA, uma câmara técnica ou um corpo técnico' (Entrevistado 01). Ainda, conforme o Entrevistado 03:

[...] a Prefeitura não conta com profissionais eficientes na área. Acho que tem que ficar com os órgãos competentes mesmo. O Município não deveria assumir essa responsabilidade. É, porque não tem profissional suficiente para fazer isso. Então, você vê uma Secretaria de Agricultura e Meio Ambiente no Município que só tem um secretário que só cuida da parte de agricultura [...] E tem um prestador de serviço que organiza um pouco da parte ambiental. Mas, dentro do quadro de profissionais da Prefeitura, não tem biólogo, não tem um agrônomo, não tem um engenheiro ambiental, florestal.

Assim, concluiu-se que o corpo técnico do CODEMA cedido por meio da parceria não seria suficiente para realização do licenciamento ambiental em nível municipal, posto que é necessário um maior número maior de técnicos, multidisciplinares, com inteira e constante disposição ao município.

\section{Proposição de instituição de unidades de conservação}

As Unidades de Conservação - UCs são previstas na lei do SNUC - Sistema Nacional de Unidades de Conservação (Lei no. 9985/2000) e são compreendidas como espaços territoriais constituídos por recursos naturais nas quais são aplicadas garantias adequadas de proteção (BRASIL, 2000). As UCs são consideradas ainda como mecanismos para a preservação dos recursos naturais e responsáveis pela manutenção da diversidade biológica no território nacional e nas águas jurisdicionais (HASSLER, 2005). No entanto, apenas a criação formal destas UCs não é suficiente se não forem utilizadas conforme seu propósito inicial de proteção ambiental, caso que foi constatado em uma pesquisa que avaliou as condições do parque Nascentes do Belém (Curitiba- PR). Segundo o estudo, a UC encontrava-se com problemas estruturais como a presença de um cemitério na vertente oposta e não se desenvolvia programas de EA sobre a importância dos recursos hídricos e do próprio Rio Belém (ZAFALON et al., 2012). No município do CODEMA foco desta pesquisa, ainda não existe nenhuma Unidade de Conservação no âmbito municipal, uma vez que a área prevista na composição judicial entre Prefeitura e Ministério Público, trata-se de uma área verde, embora tenha sido citada como tal pelo entrevistado 02 'É, a gente tem uma área que a gente quer fazer um Parque Ecológico, que é ali no final da Avenida das Nascentes, uma área grande que a gente pretende fazer ali um Parque Ecológico, Parque Municipal. A gente está começando a avaliar, começando a conversar sobre isso'. Assim, verificou-se a necessidade de um levantamento de possíveis áreas que possam ser transformadas em Unidade de Conservação para sua maior proteção.

\section{Deliberação sobre a emissão de alvarás, certidões de localização ou declaratórias}

No CODEMA, foco deste estudo, verificou-se que a plenária em ATA do dia 14/06/2018, deliberou 
acerca da regularização da atividade de extração de areia, que muitas vezes causam o assoreamento do recurso hídrico: '[...] após discussão, deliberou-se para o indeferimento da regularização ambiental e intervenção em APP, pois impacta o ambiente, ocasionando o carreamento de sedimentos e materiais argilosos para o curso hídrico, um córrego neste caso específico, causando seu assoreamento [...]'.

A decisão da plenária coaduna com o afirmado por Almeida Neto et al. (2011), ao mencionarem que os processos extrativistas resultaram em impactos ambientais frequentes aos recursos hídricos, posto que sua matéria-prima, areia, é extraída principalmente do leito dos cursos d'água.

\section{Opinar nos estudos sobre o uso, ocupação e parcelamento do solo urbano}

No município do CODEMA analisado, além da Lei Complementar Municipal n.o 002/1997 que regulamenta o uso e o parcelamento do solo urbano que deve ser observada na aprovação de loteamentos, foi promulgado o Decreto n.o 945/2017 que aprova o Manual de Procedimentos para Análise e Aprovação de Loteamentos Particulares. Segundo este instrumento legal, após o recebimento do anteprojeto de parcelamento, o processo administrativo será encaminhado ao CODEMA e, após, à Secretaria Municipal de Agricultura, Pecuária e Meio Ambiente para análise da viabilidade ambiental e locacional do parcelamento, sendo que caso não seja aprovado por esses órgãos ambientais, será encerrado e arquivado.

Em uma das atas do CODEMA pesquisado, foi possível identificar a análise de projetos de loteamento que foram aprovados com ressalvas para garantir a permeabilidade do solo:

[...] o segundo item de pauta, a análise do Projeto paisagístico/arborização e PTRF - Projeto Técnico de Reconstituição da Flora do Loteamento, ambos os projetos foram aprovados por unanimidade com as seguintes ressalvas: substituir o pavimento com calçamento de concreto por pavimento intertravado permeável, visando contribuir com a permeabilidade da água [...] Além disso, para atender o programa de coleta seletiva do município, fazer a substituição do modelo de lixeira por lixeiras do tipo coleta seletiva.

Em outro momento, percebeu-se que os conselheiros analisaram o sistema de drenagem de águas pluviais e de esgoto do projeto de loteamento, associando-o à prevenção de alagamentos e inundações e condicionando-o ao estudo de vazão, caso fosse necessário:

[...] foi apresentado o anteprojeto e o projeto de compensação do loteamento J.E. para análise da viabilidade ambiental e locacional do empreendimento [...] o conselheiro $\mathrm{N}$. indagou se o sistema de drenagem de águas pluviais e de esgoto deste loteamento seria direcionado para a microbacia do córrego da Avenida P.H. ou se seria direcionado para a microbacia do curso d'água conhecido como 'Ribeirãozinho' que passa nos fundos do bairro V. L. e região [...] foi informado que seria direcionada para o Ribeirãozinho [...] N. e outros conselheiros disseram que caso a drenagem fosse direcionada para o córrego da Avenida P.H, seria necessário que o empreendedor apresentasse um estudo de vazão do município para evitar que aconteçam alagamentos e inundações naquela área.

Constatou-se que os conselheiros do CODEMA pesquisado possuem um conhecimento sobre a importância de um planejamento no uso e ocupação do solo, principalmente devido à necessidade de manutenção da permeabilidade do solo que contribui para a diminuição do escoamento superficial no período de chuvas, evitando assim a sobrecarga no sistema de microdrenagem e, consequentemente, alagamentos e inundações. Além disso, este planejamento contribui para o ciclo da água, evitando a perda da cobertura vegetal por pavimentos impermeáveis, aumentando a infiltração da água no solo e diminuindo 
a sua quantidade e a sua velocidade de escoamento, e, por conseguinte, prevenindo a ocorrência de escassez e a diminuição da qualidade dos recursos hídricos (SANTOS et al., 2017). Em outra análise, identificou-se que o CODEMA se atentou para a necessidade do Projeto Técnico de Reconstituição da Flora - PTRF e do projeto da praça, área institucional exigida em lei: 'art. 4ํㅗ $\$ 2 ㅇ ㅡ$ - As áreas institucionais de loteamentos são aquelas destinadas à edificação de equipamentos comunitários, tais como praças, ginásio de esportes, áreas de lazer, escolas, postos de saúde, entre outros' (BRASIL, 1979), conforme descrito na ata:

Este empreendimento já foi analisado e já teve sua licença prévia autorizada por este conselho. Considerando que não houve mudança no projeto, que o empreendedor atendeu as solicitações feitas pelo CODEMA no PTRF e no Projeto da Praça e nenhum outro órgão ou departamento público ou privado apresentou objeção ao loteamento, o conselho deliberou positivamente para a concessão da LI - Licença de Instalação.

Com relação aos loteamentos que são passíveis de licenciamento a nível estadual, segundo o manual, o CODEMA também deverá analisar o projeto, como constatado em ata:

\begin{abstract}
Analisado o projeto de arborização e o PTRF e ainda tendo em vista que o licenciamento ambiental deste loteamento é de nível estadual, o conselho deliberou pela aprovação do projeto com as seguintes condicionantes: 1a - O empreendedor só poderá iniciar as supressões vegetais após a aprovação do PTRF e emissão pelo IEF da ASV. 2a - O empreendedor só poderá iniciar as obras de instalação do loteamento após emissão pela SEMAD da licença ambiental; 3a - O empreendedor deverá protocolar cópia autenticada de cada documento citado acima (ASV [autorização de supressão de vegetação] e Licença Ambiental) junto à Prefeitura Municipal para prosseguimento do processo de aprovação do loteamento.
\end{abstract}

Foi também foi analisado o Projeto Paisagístico/Arborização de um Loteamento que foi aprovado, mas com ressalvas:

Sobre o primeiro item da pauta, análise do Projeto Paisagístico do Loteamento, o mesmo foi aprovado por unanimidade com as seguintes ressalvas: o empreendedor deverá retirar a 'murtha' da lista de espécies de árvores sugeridas para a arborização, pois a mesma serve de hospedeira para o inseto transmissor da praga do Greening, uma das mais problemáticas da citricultura, que coloca em risco os laranjais da região. Além disso, o empreendedor deve atender ao §2o do art. 24 da lei 640/2017, o qual determina que o empreendedor é responsável pela manutenção da arborização pelo período de 5 (cinco) anos.

Portanto, identificou-se que grande parte da demanda do CODEMA analisado concentra-se na análise de loteamentos, inclusive foi realizada uma assembleia extraordinária só para análise de um loteamento específico. Também foi constatada a realização de uma reunião extraordinária e uma ordinária para a desafetação de uma área verde, transformando-a em área de uso público para construção de um campo de malha:

Tendo todos os conselheiros, ciência do parecer jurídico realizado pela procuradoria do município com relação à desafetação de área verde e afetação da mesma como área de Uso Público para a construção de um campo de Malha, iniciou-se a deliberação sobre o assunto. Os conselheiros N., N., P. e L. colocaram-se a favor do Projeto de Lei desde que a área verde remanescente fosse recuperada para exercer a função para a qual foi destinada.

De acordo com o Art. 8ํ, $\S 1$, da Resolução CONAMA № 369/2006, considera-se área verde de domínio público 'o espaço de domínio público que desempenhe função ecológica, paisagística e recreativa, propiciando a melhoria da qualidade estética, funcional e ambiental da cidade, sendo dotado de vegetação e espaços livres de impermeabilização', como por exemplo, os parques, praças, jardim botânico etc. No caso em análise, não foi possível realizar uma vistoria 'in loco', mas o entrevistado 02 afirmou que área verde 
desafetada apenas possuía essa nomenclatura, mas de fato estava descaracterizada como tal: 'Essa área verde, na verdade, ela não tem nada de verde lá, sabe? Lá já tem um campo de malha que o pessoal usa lá. Nós votamos pra desafetar, desde que o restante da área fosse arborizado e também uma praça que tem lá perto que fosse arborizada. E nós desafetamos uma parte, a outra será área verde'.

As condições impostas como medida de compensação pela desafetação da área verde pelo CODEMA relatadas pelo entrevistado acima, também constaram em ata:

[...] foi acrescentado um artigo que determina que o Poder Executivo deverá revitalizar a área verde remanescente da área desafetada e também a área verde do bairro J.C., ao lado do Ginásio Poliesportivo F.C. que está na mesma região. Considerando que tal condição visa melhorar a qualidade ambiental do município, os conselheiros manifestaram-se favoráveis ao Projeto de Lei.

Estas desafetações precisam ocorrer em caráter de exceção e precisam prever medidas de compensação e/ou mitigadoras, conforme foi realizado no CODEMA pesquisado, conjugando-se ainda à análise técnica por meio de Estudo de Impacto Ambiental e Estudo de Impacto de Vizinhança, isso devido à importância dessas áreas destinadas aos propósitos de recreação, lazer, melhoria da qualidade ambiental urbana, proteção dos recursos hídricos, manutenção ou melhoria paisagística, proteção de bens e manifestações culturais (BRASIL, 2012; SINHORIN, 2015; RODRIGUES et al., 2019).

\section{Autorização de intervenção em APP}

Pela análise das atas de reuniões do CODEMA, após a sua última restruturação, foi possível perceber algumas decisões sobre a autorização de intervenção em APPs urbanas. No caso abaixo, percebe-se que a plenária indeferiu a intervenção em APP de nascentes por ausência de informação e relatório:

[...] prosseguindo com a pauta, o secretário apresentou o requerimento do Sr., o qual solicita intervenção em APP em área urbana. $O$ empreendedor quer fazer três platôs no terreno e canalizar duas nascentes para um só ponto e fazer um chafariz. Por falta de informações mais amplas e de um relatório do projeto apresentado, o conselho indeferiu a intervenção na área de preservação permanente [...].

Em outro caso, baseado na utilidade pública, se decidiu pela autorização de intervenção na APP:

[...] foi lida a pauta que trata de requerimento do SAAE para intervenção em APP em zona urbana [...] O conselho, de forma unânime, aprovou a autorização da intervenção em APP urbana sem supressão vegetal, visto que a obra trará benefícios, pois canalizará o esgoto sanitário, impedindo que o mesmo acumule no local.

Em um terceiro caso, deliberou-se por não autorizar a intervenção por considerá-la de alto impacto ambiental, conforme ata 13/09/18: 'CODEMA deliberou por não autorizar que o SAAE atenda as exigências da proprietária do terreno, haja vista que as solicitações são intervenções de consideráveis impactos em APP (desvio de curso d'água natural e aterro de APP)'. Também foi possível verificar uma decisão de indeferimento da intervenção em APP pela Plenária para proteger um corpo hídrico dos impactos ambientais e assoreamento, que um empreendimento causaria ao armazenar argila em área aberta:

[...] que trata da análise e deliberação do requerimento protocolado junto ao departamento de meio ambiente da prefeitura para regularização ambiental em intervenção em APP do empreendimento [...] sendo que o empreendedor alega que utiliza a área para deposito de argila e informa que não houve supressão vegetal no local. [...] após discussão, deliberouse para o indeferimento da regularização ambiental e intervenção em APP, considerando 
que a atividade de armazenamento de argila em área aberta e, principalmente em APP, impacta negativamente o ambiente, ocasionando carreamento de sedimentos e materiais argiloso para o curso hídrico, um córrego neste caso específico, causando o seu assoreamento.

Nota-se que a intervenção em APP é exceção, e só deve ser concedida nos casos de utilidade pública, de interesse social ou de baixo impacto ambiental, conforme preceitua o art. 8ㅇ do Código Florestal (BRASIL, 2012). Ainda, segundo os entrevistados, o CODEMA contribui para a conservação dos recursos hídricos ao autorizar intervenções em APPs, principalmente, devido às nascentes e a conservação das matas ciliares. Cita-se como exemplo o seguinte relato:

Estava colocando o material, a argila dentro de uma área de preservação permanente que ficava próxima a um curso d'água e queria a licença para poder fazer isso. É intervenção, não suprimir a vegetação, mas poder depositar ali. E a primeira coisa que foi falada é que seria impossível, justamente por causa desse córrego, assoreamento e tal. Então, eu acho que o CODEMA é para essas questões. A questão de nascente, a gente tem muita nascente aqui. É muito importante a gente poder deliberar sobre essas questões, para que não tenha a supressão de área que tenha que ter vegetação para que esses cursos d'água não venham morrer. (Entrevistado 03)

Igualmente, o Promotor de Justiça se manifestou aduzindo que toda demanda que envolva recurso hídrico municipal passa pelo crivo do CODEMA que também é o ente responsável por autorizar a intervenção em APP Urbana:

Bem, os CODEMAS, como eu disse, são a instância deliberatória do Município, então, assim, toda a criação de política pública que verse sobre recurso hídrico municipal passa pelo CODEMA. Além disso, eu não vou me recordar agora o número da DN -Deliberação Normativa do COPAM, mas, na área urbana dos Municípios, é o CODEMA quem autoriza a intervenção nas áreas de preservação permanente. (Entrevistado 04).

O Promotor de Justiça, conforme acima descrito, ao mencionar sobre a DN COPAM que remetia a competência ao CODEMA para autorizar a intervenção em APP urbana, provavelmente referia-se à DN COPAM 76/04 que foi revogada em 25/07/18 pela DN COPAM 226/18, data posterior à realização da entrevista. Essa nova DN 226/18 não prevê expressamente sobre essa competência, no entanto, no âmbito federal, ainda permanecem as disposições da Lei Complementar no. 140/2011 e da Resolução CONAMA no. 369/06. Assim, pode-se interpretar que sendo de competência do município e ele possuindo CODEMA deliberativo, caberá a este órgão a competência para autorizar a intervenção em APP urbana desde que esta solicitação não seja resultante de empreendimento sujeito a licenciamento ambiental de nível estadual.

No entanto, foi constatado que, embora o CODEMA pesquisado exerça essa competência, ela não está prevista na sua lei de reestruturação ou em seu Regimento Interno.

\section{CONCLUSÕES}

Apesar de prever em sua lei de criação vinte e sete competências, constatou-se no período da pesquisa e por meio dos relatos dos entrevistados a concentração do CODEMA em deliberações sobre loteamentos, autorização de poda e de corte, análise de alvará de localização e autorização em intervenção em APP urbana. As ações em EA ainda são incipientes diante da necessidade de se conscientizar a população, principalmente sobre a importância de sua participação na gestão ambiental municipal e o seu papel na conservação dos recursos hídricos. Além disso, percebeu-se que ele ainda não está totalmente estruturado 
para realização do licenciamento, embora essa competência possa trazer benefícios econômicos para o município. Também foi possível perceber a importância das deliberações do CODEMA na conservação dos recursos hídricos de forma indireta e direta principalmente no exercício de suas competências, como na análise da viabilidade locacional e ambiental de loteamentos, na análise de alvará de localização e na autorização em APP urbana, respeitando os casos de utilidade pública, interesse social ou baixo impacto ambiental. Com relação à percepção dos entrevistados quanto às competências desempenhadas pelo CODEMA, os conselheiros apresentaram a necessidade de ações de EA e de mobilização da sociedade, bem como demonstraram conhecimento sobre a relação dos recursos hídricos com as atividades do CODEMA, principalmente, por meio das autorizações de intervenção em APPs. Ao mesmo passo, percebeu-se em vários momentos decisões da plenária em prol dos recursos hídricos baseados em conhecimentos técnicos dos conselheiros.

O CODEMA foi apontado ainda, como catalizador de informações e defensor dos recursos hídricos pelo representante do Ministério Público. Portanto, é essencial o reconhecimento e aplicabilidade da gestão ambiental municipal integrada a de recursos hídricos, principalmente pelo seu impacto positivo sobre a ordenação e uso ocupação do solo. Quanto às limitações, não se pode generalizar os dados adquiridos para outros CODEMAs, já que cada um possui suas próprias competências delimitadas na lei de sua criação.

\section{REFERÊNCIAS}

AMARAL, E. A.; PEREIRA, S. G.; BORGES, D. C. S.. Avaliação de impactos ambientais em uma área de preservação permanente no bairro Céu Azul, em Patos de MinasMG. Revista do Centro Universitário de Patos de Minas, v.2178, p.16-26, 2013.

ALMEIDA NETO, J. V.; OLIVEIRA, A. K. M.; BONONI, V. L. R.. Atuação do Conselho Municipal do Meio Ambiente em Campo Grande, MS: licenciamento ambiental. Revista Brasileira Multidisciplinar, v.14, n.1, p.158-168, 2011. DOI: https://doi.org/10.25061/25272675/rebram/2011.v14i1.105

ASSIS, P. C.; GODOY, A. M. G.. O conselho de defesa do meio ambiente de Maringá: Governança, poderes e decisões na gestão dos recursos hídricos. Revista de Ciências Jurídicas e Empresariais, v.9, p.19-24, 2008.

ÁVILA, R. D.; MALHEIROS, T. F.. O sistema municipal de meio ambiente no Brasil: avanços e desafios. Saúde e Sociedade, v.21, p.33-47, 2012. DOI: http://dx.doi.org/10.1590/S0104$\underline{12902012000700004}$

BABAYEMI, J. O.; OGUNDIRAN, M. B.; OSIBANJO, O.. Current levels and management of solid Wastes in Nigeria.

Environmental Quality Management, v.26, p.29-53, 2017. DOI: https://doi.org/10.1002/tqem.21498

BRASIL. Lei n. 6766, de 19 de dezembro de 1979. Dispõe sobre o Parcelamento do Solo Urbano e dá outras Providências. Brasília: DOU, 1979.

BRASIL. Lei complementar n.140, de 09 de dezembro de 2011. Fixa normas, nos termos dos incisos III, VI e VII do caput e do parágrafo único do art. 23 da Constituição
Federal, para a cooperação entre a União, os Estados, o Distrito Federal e os Municípios nas ações administrativas decorrentes do exercício da competência comum relativas à proteção das paisagens naturais notáveis, à proteção do meio ambiente, ao combate à poluição em qualquer de suas formas e à preservação das florestas, da fauna e da flora; e altera a Lei no 6.938, de 31 de agosto de 1981. Brasília: DOU, 2011.

BRASIL. Lei n. 12. 651, de 25 de maio de 2012. Institui o Código Florestal Brasileiro. Brasília: DOU, 2012

BRASIL. Lei $\mathbf{n} . \mathbf{9 . 9 8 5}$, de $\mathbf{1 8}$ de julho de 2000. Regulamenta o art. 225, § 10, incisos I, II, III e VII da Constituição Federal, institui o Sistema Nacional de Unidades de Conservação da Natureza e dá outras providências. Brasília: DOU, 2000.

CARVALHO, P. G. M.; OLIVEIRA, S. M. M. C.; BARCELLOS, F. C.; ASSIS, J. M.; CARVALHO, P. G. M.. Gestão local e meio ambiente. Ambiente e sociedade, v.8, p.121-140, 2005. DOI: https://doi.org/10.1590/s1414-753×2005000100008

CARVALHO, M. R. B.; LEITE, J. C.. Reverse Logistics and selective waste collection: environmental education as an auxiliary tool on the process of recycling of domestic electronic waste. Business Management Dynamics, v.5, p.22-41, 2016

CASTRO, M. L.; GEISER, S. R. A.; PHILIPPI, J. R.; OGERA, R. C.; SALLES, C. P.. O conselho municipal de meio ambiente na formulação de políticas públicas. In: PHILIPPI, J. R.; MAGLIO, I. C.; FRANCO, R. M.. Municípios e meio ambiente: perspectivas para a municipalização da gestão ambiental no Brasil. São Paulo: Associação Nacional de Municípios e Meio Ambiente, 1999. p.47-59. 
CHOON, S.; TAN, S.; CHONG, L.. The perception of households about solid waste management issues in Malaysia. Environment, Development \& Sustainability, v.19, p.1685-1700, 2017. DOI: https://doi.org/10.1007/s10668$\underline{016-9821-8}$

COLLIS, J.; HUSSEY, R.. Pesquisa em administração: um guia prático para alunos de graduação e pós-graduação. Bookman, 2005.

CONAMA. Conselho Nacional de Meio Ambiente. Resolução CONAMA n. 237, de 19 de dezembro de 1997. Brasília: CONAMA, 1997.

CONTRERA, J. M. A. D.; ALMEIDA, F. S.; SANTOS, A. C.; ANDRADE, T. A. G.. Análise da gestão de resíduos sólidos urbanos nos municípios do estado do Rio de Janeiro e o papel dos aterros sanitários na diminuição dos impactos ambientais. Anuário do Instituto de Geociências, v.41, p.178-185, 2019. DOI:

http://dx.doi.org/10.11137/2018 3178185

COPAM. Conselho Estadual de Política Ambiental. Deliberação Normativa n. 369, de 28 de março de 2006. Dispõe sobre os casos excepcionais, de utilidade pública, interesse social ou baixo impacto ambiental, que possibilitam a intervenção ou supressão de vegetação em Área de Preservação Permanente-APP. Brasília: DOU, 2006.

COPAM. Conselho Estadual de Política Ambiental. Deliberação Normativa COPAM n. 213 de 22 de fevereiro de 2017. Regulamenta o disposto no art. 99, inciso XIV, alínea 'a' e no art. 18, § 2ㅇ da Lei Complementar Federal no 140, de 8 de dezembro de 2011, para estabelecer as tipologias de empreendimentos e atividades cujo licenciamento ambiental será atribuição dos Municípios. Brasília: DOU, 2017.

CORNELLI, R.; SCHNEIDER, V. E.; BORTOLIN, T. A.; CEMIN, G.; SANTOS, G. M.. Análise da Influência do Uso e Ocupação do Solo na Qualidade da Água de Duas Sub-Bacias Hidrográficas do Município de Caxias do Sul. Scientia cum Industria, v.4, n.1, p.1-14, 2016. DOI: https://doi.org/10.18226/23185279.v4iss1p1

FERREIRA, N. C. F.; DUARTE, J. R. M.; OLIVEIRA, L. A. B.; SILVA, E. C.; CARVALHO, I. A.. O papel das matas ciliares na conservação do solo e água. Biodiversidade, v.18, n.3, 2019.

GALVÃO, J.; BERMANN, C.. Crise hídrica e energia: conflitos no uso múltiplo das águas. Estudos avançados, v.29, n.2, p.43-68, 2015. DOI: https://doi.org/10.1590/s0103$\underline{40142015000200004}$

GIBBS, G.. Análise de dados qualitativos. Porto Alegre: Artmed, 2009.

JIA, X.; WANG, S.; LI, Z.; WANG, F.; TAN, R. R.; QIAN, Y.. Pinch analysis of GHG mitigation strategies for municipal solid waste management: A case study on Qingdao City. Journal of Cleaner Production., v.174, p.933-944, 2018. DOI: https://doi.org/10.1016/j.jclepro.2017.10.274

LAW, M. M. S.; HILLS, P.; HAU, B. C. H.. Engaging Employees in Sustainable Development - a Case Study of Environmental Education and Awareness Training in Hong Kong. Business
Strategy \& the Environment, v.26, p.84-97, 2017. DOI: https://doi.org/10.1002/bse.1903

LEME, T. N.. Os municípios e a política nacional do meio ambiente. Planejamento e Políticas Públicas, v.2, p.25-52, 2010.

LUCON, T. N.; PRADO FILHO, J. F.; SOBREIRA, F. G.; BOKIKIAN, C. T.. Análise das áreas de preservação permanente do perímetro urbano de Ouro Preto (MG). Revista da Sociedade Brasileira de Arborização Urbana, v.6, n.4, p.107-124, 2019. DOI:

https://doi.org/10.5380/revsbau.v6i4.66491

MALHOTRA, K. N.. Pesquisa de Marketing: uma orientação aplicada. 4 ed. Porto Alegre: Bookman, 2006.

NOVICKI, V.; SOUZA, D. B.. Políticas públicas de educação ambiental e a atuação dos Conselhos de Meio Ambiente no Brasil: perspectivas e desafios. Ensaio: avaliação e políticas públicas em Educação, v.18, n.4, p.711-736, 2010. DOI: https://doi.org/10.1590/s0104-40362010000400004

OLIVEIRA, R. C. M.; LIMA, P. V. P. S.; SOUZA, R. P.. Gestão ambiental e gestão dos recursos hídricos no contexto do uso e ocupação do solo nos municípios. Gestão \& Regionalidade, v.33, n.97, p.48-64, 2017. DOI: https://doi.org/10.13037/gr.vol33n97.3101

OLUWATUYI, A. D.; ADEDIJI, A.; ADEOLA, A.. Evaluation of human-environment interaction in river Ominla riparian corridor in ore township, ondo state, South western Nigéria. Scholedge International Journal of Management \& Development, v.4, p.1-9, 2017. DOI: https://doi.org/10.19085/journal.sijmd040101

PARDO-MARTÍNEZ, C.; PIÑA, W.. Solid waste management in Bogotá: the role of recycling associations as investigated through SWOT analysis. Environment, Development \& Sustainability, v.19, p.1067-1086, 2017. DOI: https://doi.org/10.1007/s10668-016-9782-y

PEIXOTO, F. S.; RODRIGUES, J. P. B.; ALBUQUERQUE, P. I. M.. Gestão integrada dos recursos hídricos e a problemática das inundações urbanas. Geografia, Londrina, v.28, n.1, p.187206, 2019. DOI: https://doi.org/10.5433/24471747.2019v28n1p187

RODRIGUES, F. R.; LOPES, E. R. N.; LOURENÇO, R. W.. Análise integral dos impactos urbanos em áreas verdes: uma abordagem em Sorocaba, Brasil. Raega: O Espaço Geográfico em Análise, v.46, n.2, p.135-151, 2019. DOI: http://dx.doi.org/10.5380/raega.v46i2.61224

SANTOS, K. A.; RUFINO, I. A. A.; BARROS FILHO, M. N. M.. Impactos da ocupação urbana na permeabilidade do solo: o caso de uma área de urbanização consolidada em Campina Grande-PB. Engenharia Sanitária e Ambiental, v.22, p.943952, 2017. DOI: https://doi.org/10.1590/s1413$\underline{41522016146661}$

SILVA, T. F.. Análise do processo erosivo no loteamento paraíso - Itajubá - MG. Dissertação (Mestrado em Meio Ambiente e Recursos Hídricos) - Universidade Federal de Itajubá, Itajubá, 2015. 
SINHORIN, J. A.. Desafetação de áreas verdes urbanas: uma solução ao problema através do princípio da concordância prática. In: ENCONTRO ANUAL DE INICIAÇÃO CIENTÍFICA DA UEL. Anais. Londrina, 2015.

STAKE, R. E.. The case study method in social inquiry. In: NORMAN, K. D.; YVONA, L. S.. The American tradition in qualitative research. 2 ed. Thousand Oaks: Sage Publications, 2000.

VARELA-CANDAMIO, L.; NOVO-CORTI, I.; GARCÍA-ÁLVAREZ, M. T.. The importance of environmental education in the determinants of green behavior: A meta-analysis approach. Journal of Cleaner Production, v.170, p.1565-1578, 2018. DOI: $\underline{\text { https://doi.org/10.1016/j.jclepro.2017.09.214 }}$
SIMATELE, D. M.; DLAMINI, S.; KUBANZA, S.. From informality to formality: Perspectives on the challenges of integrating solid waste management into the urban development and planning policy in Johannesburg, South Africa. Habitat International, v.63, p.122-130, 2017. DOI: https://doi.org/10.1016/j.habitatint.2017.03.018

YIN, R. K.. Estudo de caso: planejamento e métodos. São Paulo: Bookman, 2005.

ZAFALON, R.; SILVA, S. K.. A criação de unidades de conservação como instrumento de proteção aos recursos hídricos: estudo de caso do Parque nascentes do BelémCuritiba, PR. Geografar, v.7, p.126-152, 2012. DOI: https://doi.org/10.5380/geografar.v7i2.24640 